\title{
THE "INFUSION" METHOD AT UCLA: TEACHING ETHICS PERVASIVELY
}

\author{
CARRIE MENKEL-MEADOW* AND RichaRd H. SANDER ${ }^{* *}$
}

I

\section{INTRODUCTION}

Although virtually all law schools teach "legal ethics," few standard parts of the curriculum are taught in so many different ways. At UCLA, this diversity of approach has followed from the presence of an unusual concentration of scholars writing about different aspects of legal ethics and the legal profession, who sought to link their research to their teaching in the field. Over the years, UCLA students have learned about "legal ethics" and the sociology of the legal profession from such scholars as David Mellinkoff, ${ }^{1}$ Murray Schwartz, ${ }^{2}$ Richard Abel, ${ }^{3}$ Cruz Reynoso, ${ }^{4}$ and the authors of this essay. ${ }^{5}$

Thus, from the beginning, the focus on teaching about legal ethics and the legal profession at UCLA was on the diversity of ways of teaching and learning about different aspects of legal ethics and the legal profession. Informed by a professorial culture that took seriously all constituent disciplines in the teaching of professional responsibility - the rules of the "law of lawyering," moral philosophy, sociology, economics, clinical and practical instruction, judicial ethics and ethics enforcement-we sought to introduce both our fellow colleagues and our students to the many layers and levels of issues implicated in the legal ethics of lawyers. With funding from the W.M. Keck Foundation, we hoped to develop "pervasive" ethics teaching, not only by "infusing" ethics throughout the curriculum but by "infusing" it throughout all levels of the legal profession-students, law faculty, practicing lawyers, scholars, and judges. The Keck Working Group was formed, whose leaders (Richard Abel and the authors of this essay) were linked by some common concerns: the effects of the organizational structure of work on legal ethics and practice; the links to actual practice of ethical dilemmas; and the teaching of an "ethical methodology" for

\footnotetext{
Copyright $(1996$ by Law and Contemporary Problems

* Professor of Law and Co-Director, Center for Conflict Resolution, UCLA.

** Professor of Law, UCLA.

1. THE CONSCIENCE OF A LAWYER (1973)

2. Lawyers and the Legal Profession: Cases and Materials (2d ed. 1985).

3. AMERICAN LAWYERS (1989); LAWYERS IN SOCIETY (Richard L. Abel \& Philip S.C. Lewis eds., 1988-89).

4. The Law and Law Schools, 1970 U. TOL. L. REV. 809 (1970).

5. Murray Schwartz \& Carrie MenKel-Meadow, Lawyers and the Legal Profession (Supp. 1987); Carrie Menkel-Meadow, Culture Clash in the Quality of Life in the Law: Changes in the Economics, Diversification and Organization of Lawyering, 44 CASE WESTERN RES. L. REV. 621 (1994); Richard H. Sander \& E. Douglas Williams, Why Are There So Many Lawyers? Perspectives on a Turbulent Market, 14 LAW \& SOCIAL INOUIRY 421 (1989).
} 
making decisions where rules were less than clear or unambiguous and lawyers were called upon to consult their own personal and professional ethics.

Because UCLA has a strong commitment to diversifying the profession and to a nationally recognized clinical program, we were also concerned that our teaching of legal ethics should inform students about what it means to practice law in a profession that is becoming both demographically and substantively more diverse, and that legal ethics should be linked practically and instrumentally to how lawyers actually conduct themselves. The Keck group leaders all had empirical backgrounds of varying degrees and were eager to evaluate our program rigorously and to determine what ethics issues were really confronting the bar and our student body.

We were motivated to teach ethics pervasively (that is, in the substantive courses across the curriculum) for many different reasons. Some of us were hoping that the pervasive method would eventually replace our required upperlevel courses, freeing some of us to teach more sophisticated and specialized ethics courses, on topics such as lawyering and social change, ethics issues in alternative dispute resolution, the sociology of the legal profession, and ethics in particular practice settings. Others of us thought that the required courses could never be replaced because they were the source of detailed and systematic treatment of rules, codes, and other legal ethics issues. All of us thought that ethics should be addressed within the standard law school curriculum $^{6}$ because lawyers are likely to encounter legal ethics problems while working on substantive matters. We also recognized that our students were viewing ethical dilemmas from their part-time and summer work experiences, and we were interested in exploring how we could harness this real-world experience to the teaching of and learning about legal ethics. ${ }^{7}$ We thought, at the very least, our students should know how to recognize a legal ethics issue, even if they could not immediately find "the right answer." to instill some sense of individual responsibility, self-regulation, moral and professional questioning, and concern for the public interest and welfare. We were interested in learning about whether instructional changes and interventions could really make a difference so late in the educational process.

Some of us were especially interested in developing a professional environment in which we could reflect on our teaching methods and learn new ones. One of our number had experimented for many years with teaching professional responsibility through the use of role-plays and participatory and experiential learning, ${ }^{9}$ attempting to link rules instruction with both the sociology and moral

6. It already is implicitly, if not explicitly, taught in the substantive curriculum. See Carrie MenkelMeadow, Can A Law Teacher Avoid Teaching Legal Ethics?, 41 J. LEGAL EdUC. 3 (1991).

7. See Lawrence K. Hellman, The Effects of Law Office Work on the Formation of Law Students' Professional Values: Observation, Explanation, Optimization, 4 GEO. J. LEGAL ETHICS 537 (1991).

8. See Deborah L. Rhode, Ethics by the Pervasive Method, 42 J. LEGAL EdUC. 31 (1992).

9. See Murray Schwartz \& Carrie Menkel-Meadow, Teachers' Manual to lawyers AND THE Legal PROFESSION (1985). 
philosophy of legal ethics in context. Our clinicians had also been experimenting with different ways to teach ethics in the context of real-world cases for many years.

We thought it would be especially fruitful to share our views of teaching in different ways in an area of law itself characterized by differences of approach, both pedagogically and substantively. We embarked on this enterprise as the legal profession was confronting some major crises-loan and thrift failures, securities frauds, police abuse, and race-charged and other notorious cases taking place in Los Angeles-which made the teaching of legal ethics both more complicated and well motivated. Over the years, the presence of such television shows as "LA Law" in our city made the teaching of legal ethics almost "pervasive" in the sense that students often asked questions about what happened the night before on television and teachers had to confront how best and rigorously to use the material that so engaged the students. We also had a cadre of major substantive casebook writers, and we were encouraged that many of them would place ethics issues in the next editions of their subjectmatter texts in a great variety of ways. ${ }^{10}$ By the end of the first phase of our project, some had added notes on ethics issues in cases; others wrote new problems or included new sections in ethics in their casebooks.

Finally, we sought to use the strength of our practicing bar and bench to advise us on how ethics problems were encountered and dealt with in our local, state, and national communities. We asked an advisory committee to consult with us on issue-spotting, pedagogy and problem development, and evaluation and review.

The method we arrived at after consultation with educators and practitioners was derived from several other "curriculum integration" projects developed at UCLA, which were designed to "re-educate" experienced faculty to use new material, based on new research or new conceptual models for approaching standard or introductory courses, ${ }^{11}$ and to utilize new teaching technologies, such as experiential exercises, film and videotape, role-playing, historical material, and real case problems.

\section{II}

\section{PROGRAM DESCRIPTION}

UCLA's project funded by the Keck Foundation was designed to create and implement an experimental method of teaching legal ethics known as the "infusion method." The intent was to provide some introductory training for

10. For Example, Michael Asimow in Administrative Law, Jesse Dukeminier in Property, Mark Grady in Torts, William A. Klein in Tax and Business Associations, William M. McGovern, Jr., in Wills and Trusts, Frances Olson in Family Law, Arthur Rosett in Contracts, and Stephen C. Yeazell in Civil Procedure.

11. One such project included integrating the new scholarship on women and people of color into introductory courses in the undergraduate curriculum in sociology, psychology, English, American studies, and interdisciplinary studies (funded by the Ford Foundation). 
interested faculty in legal ethics (in the forum that became known as the Keck Working Group) and to encourage those faculty to develop materials and exercises that would integrate legal ethics into their substantive courses.

If anything, our grant proposal underestimated the energy and zeal with which the faculty embraced the project. We decided to accelerate the beginning of the project, moving the Working Group course from the Spring of 1994 to the Fall of 1993. The fifteen funded positions in the Working Group filled quickly, ${ }^{12}$ and participants began reading background material during the summer of 1993. Beginning in August 1993, the Working Group met as a weekly seminar with five "introductory" sessions covering a dozen topics in legal ethics (including the interests in promulgation of rules, adversarialism and the requirements of partisan representation, conflicts of interests, the ethics of settlement, and lawyer responsibilities for client wrongdoing). ${ }^{13}$

For the second half of the semester, the Working Group developed more than twenty teaching problems, and the weekly seminars became exercises in experimental pedagogy as well as in legal ethics. Most of the faculty used the Working Group as a test class. Some attempted to use role-plays for the first time, and others used volunteers to stage hypothetical dilemmas. One professor presented videotapes of actual clinical exercises in which student lawyers were confronted with unexpected ethical problems. Another professor distributed a chapter of his popular civil procedure casebook that he had thoroughly revised to introduce an interconnected set of concrete problems that a lawyer could confront in representing a client, including several ethical problems. Throughout these seven weeks, the Working Group's time was split between presentations of the exercises and discussions of their effectiveness. Two sessions were devoted entirely to a more general examination of the challenges created by choosing and presenting ethical problems in substantive classes. Virtually all of the participating faculty substantially revised their exercises after getting their colleagues' input.

Throughout this period of intense faculty immersion in the Working Group process, the advisory committee-a panel of fifteen distinguished lawyers engaged in a variety of legal practice settings-provided an important background resource. The three Working Group leaders met twice with the committee, first to discuss the planning of the semester and later to report on progress and explore ways of linking committee members to the faculty member's efforts. Several sorts of collaboration bore fruit: Individual members of the advisory committee attended Working Group exercises that dealt with their practice areas; others provided written feedback on drafted exercises; and a group of tax attorneys met with us to discuss their individual approaches to ethical issues in tax law practice. To many of the faculty participants, the most

12. Participating faculty received stipends for attending weekly seminars and for writing an ethics problem with a teacher's manual for their substantive classes.

13. The Working Group course syllabus, reading list, and sample exercises are available from the authors upon request. 
striking lesson from these encounters was the pervasive influence the various ethical rules had upon lawyers in practice and the recognized need among lawyers for established institutional structures to "plan around" situations that might lead to impermissible conduct.

In the spring and fall of 1994, the faculty participants began to introduce the new exercises into their substantive courses. Some of the faculty participants who teach in more than one substantive area developed new exercises for their other courses. Faculty members with whom we talked expressed considerable satisfaction with the new material, feeling that it added a new dimension to their classes and encouraged students to think concretely about real-world problems they are likely to encounter in the practice of law. Throughout this period, we videotaped faculty participants teaching many of these exercises and secured copies of revised exercises and teacher manuals that elaborated on the rationale and goals for the exercises. We later convened "same-subject" teaching groups for Keck and non-Keck participants to view the videotapes and provide both teaching feedback and substantive reactions to the material and the classes.

In the spring of 1995, we conducted evaluation sessions aimed at understanding what the effects of the new ethics "infusion" had been upon faculty and students and how we could further promote the best effects. Three types of activity occurred as part of the evaluation: (1) two "focus groups" with students who were currently enrolled in a class using two ethics exercises; (2) faculty working sessions at which the faculty watched tapes of specific exercises and discussed them; and (3) a series of meetings among the developers and overseers of the project. These diverse activities were quite useful, and each contributed to the assessments discussed below.

\section{III}

\section{ASSESSMENTS AND LESSONS}

The Keck project has had a clear and positive effect upon the law school's faculty. An important motive for many of the participants in the Working Group was the desire to develop a greater comfort level with legal ethics. Most faculty knew much about specific doctrines in legal ethics, but they felt uncomfortable raising legal ethics issues in class because they lacked a strong sense of the field's overall structure and had insufficient detailed knowledge of how difficult issues in the field are resolved (or left unresolved). Some faculty told us that their unease with legal ethics gave them some pause in exploring other issues of legal practice in the classroom, for fear of giving a misleading sense of how the ethical questions should be factored into the analysis.

While the Working Group did not produce experts in legal ethics, it clearly gave the faculty participants a sufficient foundation to encourage their own studies. The effect on faculty has been unmistakable. Faculty members now regularly identify important questions and ambiguities in legal ethics that affect their work and conduct research or organized discussions with their colleagues to explore those issues. Two members of the Working Group have incorporated 
ethics issues into their legal scholarship,$^{14}$ producing important contributions to their academic fields and encouraging other academics outside of UCLA to pay more attention to ethical questions. A significant and growing number of casebooks produced by UCLA faculty now contain discussions or examples of how ethics intersects the books' subjects. ${ }^{15}$ A clear benefit of the Keck Project, then-and one we barely thought of in the planning stages-is the very considerable integration of ethics into the academic lives of our faculty.

One of the most important benefits of the integration is the greater presence of ethical issues in the law school classroom. As noted above, the participation of more than a third of our tenured and tenure-track faculty in the Working Group means that a large part of the law school curriculum-and probably six or more courses taken by the typical student-include an ethics component. The goal of exposing students regularly to legal ethics in the context of substantive law courses has undoubtedly been realized.

What is far harder to gauge are the effects of this change. For many students in many courses, the "ethics component" is not recognized as such; rather, it is seen as a greater attention to real-world problems of legal practice. Of course, this is part of the goal. We do not want students to think of "legal ethics" as a distinct, reified field, but as a component of daily life as a lawyer. One consequence of blurring the distinctions between substantive law and ethical issues is a greater difficulty in determining whether and to what extent attitudes toward legal ethics have changed. In our two focus groups with students, ${ }^{16}$ we asked how they would spot a "legal ethics issue" and what resources they would use to try to resolve a dilemma. We tried to uncover whether there were differences in legal ethics analysis when issues came up in the context of substantive courses. We specially inquired into the students' sources of information on lawyer ethics, both before and since entering law school, sources such as the media, prior legal work, and family models.

We learned that many of our students were somewhat cynical about legal education generally and the ability to change "selfish people" into good lawyers. However, we also learned that students liked discussing what they perceived to be ethical issues-both concrete ethical dilemmas and the bigger issues about how they use the tools of their trade, such as whether to be public interest lawyers or "hired guns." The students were anxious to have more fora for such discussions but were also uncertain about what would be the best methods to accomplish this. They considered faculty leadership important but also were concerned about peer culture and pressure and the effects of the job market and

14. See, e.g., William McGovern, Undue Influence and Professional Responsibility 28 REAL PROP., Prob. \& TR. J. 643 (1994); Clyde Spillenger, Elusive Advocate: Reconsidering Brandeis as People's Lawyer, 105 YALE L.J. 1445 (1996).

15. See, e.g., Jesse Dukeminier \& James KRIER, Property (3d ed. 1993); MARK Grady, CaSES AND MATERIAL ON TORTS (1994); STEPHEN C. YeaZell, Civil PROCEDURE (4th ed. 1996).

16. One focus group was conducted before an ethics exercise was taught in a substantive course; the other one was conducted after the exercise. 
the formation of student "affinity groups" by choice of career (public interest versus big firm) or other factors (such as gender or age).

In conducting the focus groups, we found it somewhat difficult to discover much about the teaching of legal ethics specifically; our discussions tended to focus more broadly on substantive material and on general pedagogical questions. What we did learn was that students were anxious to talk about their legal education, professional choices, and the role that legal ethics writ large plays in such choices. One caution emerges from our experience. Students who "volunteered" for our focus groups on "legal ethics" may have been unrepresentative. It would be more effective randomly to select students to participate in a discussion whose subject matter is not specifically labeled. If it is well designed, the before-and-after focus group evaluative model holds promise for evaluating legal education and legal ethics specifically.

A few conclusions do seem supported by our evaluation process and by less formal discussions within the law school community. First, we should not rely on the infusion method to teach legal ethics. Students who encounter ethics exercises in half-a-dozen courses are, in the totality of those experiences, only covering a fraction of the material covered in the traditional professional responsibility course. Additionally, there is some need to learn and absorb the unifying concepts and structure of the ethics codes-a process hard to accomplish within an "infusion" setting.

Second, the larger the proportion of faculty who use these techniques, the more effective infusion will be. Faculty members within the same area of specialization frequently discuss those subjects and exchange ideas and material for class presentations. As more faculty get over their discomfort with legal ethics, then the spread of ideas and examples dealing with ethical issues will be catalyzed. And, as the number of classes with some ethical component increases, the benefits to students will increase disproportionately; in other words, encounters with ethics in a dozen different courses is probably more than twice as beneficial as half-a-dozen encounters, because students (and professors in class) are more likely to draw connections across courses and within particular ethical topics, thus adding synergy and depth to the increasing breadth of coverage.

Third, the introduction of the infusion method has increased the need to rethink and reform our traditional ethics courses. As students become more accustomed to examining particular ethical issues in specialized, substantive contexts, they are less patient with the traditional approaches typically followed in some of the long-standing professional responsibility courses. Courses that draw on student and lawyer experiences, especially when tied to actual problems of practice, more successfully motivate students, both to learn the rules and to examine the sociological and moral context of a particular ethical problem.

We are developing strategies to redesign the ethics curriculum so that it can complement the infusion method and provide, as noted above, the structure and overarching philosophy that cannot be readily conveyed in an infusion setting. 
One clearly desirable change would be the introduction of some systematic ethics coverage early in the first year of law school, so that students will already have background and a framework when they begin to encounter ethics in their infusion courses. We will be looking closely at lessons from other law schools' Keck projects as we develop these ideas.

A fourth assessment-and the one that poses the most difficult challenge-is that we must continue to seek ways to bridge the gap between "ethics" and "legal ethics" in our curriculum. We were struck by this issue early in the advisory committee's deliberations when we realized that in some practice settings, the exploitation of legal ethics rules (for example, conflict-of-interest regulations) is viewed as a legitimate weapon in litigation (for example, disqualifying an opposing firm when there is a technical but not a substantive conflict of interest). A common reaction of faculty in the Working Group was frustration at the difficulty of using codes of legal ethics to promote ethical behavior; many of the rules either bump up against the ethical norms of daily life or implicitly encourage lawyers to counsel clients on strategies for avoiding detection. These difficulties can be especially significant when legal ethics is taught in an "infusion" setting. When a tax professor explains the practical details of how the IRS promulgates and enforces disclosure standards, she is giving her students a richer and more nuanced sense of how regulatory standards interact with ethical guidelines, thus accomplishing a key infusion goal. But when an enterprising student asks about IRS enforcement methods and how a lawyer can protect himself from a dishonest client, the discussion can easily turn toward strategy and away from ethics. This is a significant problem, and it is one that goes far beyond the pedagogical techniques of a classroom or school. We are hopeful that an important side-benefit of greater faculty attention to ethics in their own scholarly work will be more thinking and research about how to bring legal ethics and social ethics into closer harmony.

\section{IV \\ THE FUTURE}

We originally envisioned a compendium of infusion materials, compiled into publishable form by a project editor. However, soon after our project began, Stanford's Deborah Rhode developed a textbook with precisely that mission, and she developed a centralized depository at Stanford aimed at indexing classroom material in legal ethics from around the country, and making that information retrievable by interested teachers. Therefore, rather than compile our own compendium, we gave our teaching materials to Professor Rhode.

We are working to adapt two parts of the Keck "experiment" into our regular academic program. First, several junior faculty who have joined UCLA since the Keck project began have expressed a very strong interest in adapting the infusion method to their own classes. As noted above, this process is greatly facilitated by a collaborative study process in which faculty members can develop enough knowledge of the legal ethics literature to feel comfortable 
developing and teaching ethics exercises. Thus, part of any orientation of new faculty to our, or any law school, might include some collaborative dialogue among these faculty and experienced ethics faculty to consider the infusion of ethics issues into the courses at a time at which new teachers are just beginning to frame their teaching agendas.

Second, it would be useful to continue the faculty working sessions started last spring, perhaps as part of a regular "teaching group" of UCLA law faculty. At these sessions, we pair an infusion teacher with other faculty who teach in the same substantive area but who do not necessarily use infusion methods. We then show a tape of the infusion teacher using an ethics exercise in class and discuss the performance from the standpoints of pedagogic strategy, class flow, student interest, and substantive content. The sessions are highly effective in several different ways: they correct any substantive errors in the professor's exercise; encourage substantive discussions of ethics and teaching; get other faculty excited about the infusion method; and encourage faculty to include ethics exercises in their textbooks. Structured leadership and funding help to make these sessions more timely, better organized, and better staffed.

\section{CONCLUSION}

We were honored to be chosen by the Keck Foundation to participate in this national effort to invigorate the teaching and learning of legal ethics in the nation's law schools, and we are delighted with the results. Institutions are often resistant to change; yet the Keck program has produced a series of interrelated changes that are likely to grow and reinforce one another with the passage of time. The improvements in our curriculum and academic life have exceeded our expectations.

Knowledge and sophistication about legal ethics is now broader and deeper among our law faculty than at any time in our past. A typical student, who before the Keck project would have encountered ethical issues in one or two courses, is now likely to encounter those issues in at least half-a-dozen classes, usually in the context of practical, substantive dilemmas of real-world legal practice. New arrivals on the faculty quickly pick up on the awareness paid to ethical issues at UCLA and are eager to become part of the movement. The momentum created by these changes is also leading us to reexamine and improve the more traditional parts of our ethics curriculum.

Keck's support of teaching in legal ethics could be supplemented by support for empirical projects on lawyers' practices and legal ethics to study systematically the issues we teach or by support for legal ethics scholarship more generally. ${ }^{17}$ The study and teaching of legal ethics requires a catalyst to keep it front

17. There is a growing interest in ethics rule drafting in particular subject areas-disclosures in banking, securities, regulation of "ancillary" practice, the development of ethical standards for new, less adversarial methods of law practice, like alternative dispute resolution, and study of and monitoring of 
and center in the attention of legal scholars and practitioners. Where legal educators and legal education generally remain somewhat resistant to change, outside leadership and funding may be necessary. ${ }^{18}$

Although "infusing" ethics in the law school curriculum will not be the panacea for all bad lawyering behavior, an increased "ethical consciousness" and the development of an "ethical methodology" are teachable to students who hunger for opportunities (in any way they present themselves) to discuss the nature of their future professional and personal lives.

the many proposals to change, modify, or monitor criminal law and practice, following our recent notorious cases.

18. For example, the Ford Foundation's Council on Legal Education for Professional Responsibility "seed"-funded clinical education programs, which were originally designed to teach ethics and professional responsibility in the context of real practice, are now permanent fixtures in many law schools. 